\title{
Containing a Credible Loss to Within Frequency Stability Limits in a Low Inertia GB Power System
}

\author{
Marcel Nedd, Member, IEEE, Jethro Browell, Member, IEEE, Keith Bell, Member, IEEE, and \\ Campbell Booth, Member, IEEE
}

\begin{abstract}
There is a reduction in the percentage penetration of synchronous machines within the Great Britain (GB) power system leading to a decrease in inertia, and an increase in system rate of change of frequency (RoCoF) resulting from power imbalances. This raises the challenge of containing frequency deviations to within the relevant operational limits. As a result, steps need to be taken by the system operator to manage the risk to system security. In order to better understand this risk, this paper presents the challenge in light of the changing energy landscape and the current and future frequency response services available to contain frequency deviations. Although the current GB frequency response services may be capable of containing most events within frequency limits, in low inertia scenarios these responses alone are not capable of containing excursions within practical RoCoF limits. Consequently, further action must be taken to ensure system security. The system operator currently employs an interim solution of limiting the largest loss risk, depending on system inertia and the RoCoF limit. While this is suitable in the short-term, it is unlikely that this option will be cost-effective in the future.
\end{abstract}

Index Terms - frequency response; frequency containment; loss risk; low inertia; RoCoF

\section{INTRODUCTION}

$\mathrm{S}$ ustainability targets have led to the increased proliferation of low carbon, particularly renewable, generation. In Great Britain (GB), as in many countries, the two major renewable sources that have grown in recent years are wind and solar power, which are (in their majority) converter-connected, nonsynchronous, technologies. Their percentage share of generation is expected to continue to grow [1], while coal plants are expected to close [2,3] and nuclear generation has an uncertain future.

The increasing penetration of non-synchronous technologies in the power system presents challenges [4]. Traditionally, transmission connected synchronous machines have been the main sources of reserves of energy, delivered at different

M. Nedd, J. Browell, K. Bell and C. Booth are with the Electronics and Electrical Engineering Department, University of Strathclyde, Glasgow, G1 1RD UK, (e-mail: marcel.nedd@ strath.ac.uk). This work has been supported through the EPSRC Centre for Doctoral Training in Future Power Networks and Smart Grids (EP/L015471/1) with industry support from ScottishPower Energy Networks. The data for the case studies are available online at https://doi.org/10.15129/62d7586a-8efe-4616-9e3f-f0033f8f6515. timescales via inertia response, frequency containment reserve and restoration reserve. Inertia response is the instantaneous and automatic delivery of kinetic energy from synchronously connected plant rotors, via an inherent electromagnetic coupling with the network that opposes and helps correct imbalances in generation and demand. Non-synchronous generation technologies are so-called as they are connected via a solid-state electronic converter and do not have the same inherent capability of providing inertia to the system $[5,6]$. The inertia of a power system affects the rate of change of frequency (RoCoF) following a system event [6, 7]. As system inertia reduces, the $\mathrm{RoCoF}$ increases for a given power imbalance which in turn, without remedial actions, reduces the system's resilience to frequency disturbances $[8,9]$.

RoCoF relays are widely used in some countries, including the UK and Ireland, in loss of mains (LoM) protection for distributed generation $[10,11]$. These relays are designed to disconnect generation when the locally measured RoCoF exceeds a given limit for a given period of time, taken to be an indicator of disconnection from the main interconnected system [12]. If the RoCoF following a frequency disturbance on the main system is too high, it increases the risk of cascading frequency events because of the unintended tripping of RoCoF relays. Without adequate safeguards, this risk is increased in low inertia power systems. The RoCoF also influences overall deviations in system frequency, which if not kept within statutory limits via additional containment and restoration response services risks the triggering of under- or over-frequency protection on generators or of under-frequency load shedding.

These risks inform operational limits, relating to both $\mathrm{RoCoF}$ and minimum or maximum frequency excursions that the system operator must ensure are respected in the event of a credible disturbance. Systems already experiencing operational scenarios in which credible loss of infeed (LoIF) events within normal security standards gives rise to concern include those on the island of Ireland and in GB.

In a system with decreasing levels of system inertia the challenge of complying with RoCoF and frequency limits following a credible loss event increases. In this context, this paper investigates and discusses different actions to manage and contain a credible loss risk in a low inertia GB power system. The actions considered in this paper include curtailing 
the loss risk, deploying existing frequency response services, and deploying additional faster response services. The main contributions of this paper are as follows:

- it is shown that at very low inertia, scheduling more reserve holding of comparatively slow dynamic containment response services is incapable of containing a loss of infeed event within frequency limits;

- it is also shown that under the current $0.125 \mathrm{~Hz} / \mathrm{s} \mathrm{RoCoF}$ limit, present and future frequency containment products, as they are defined, are not sufficiently fast acting to contain a normal loss of infeed event within the RoCoF limit. At present, the only viable options deployed in GB are either or both constraining the loss risk or the system inertia; and

- a faster response service is important and there is a need for fast acting, and indeed rapidly deliverable, response services even at a relaxed RoCoF limit in order to contain a loss event within both frequency and RoCoF limits. This need is shown to become more dominant as the GB power system tend towards lower inertia and the RoCoF limit of $1 \mathrm{~Hz} / \mathrm{s}$.

This paper is structured as follows: Section II describes frequency and RoCoF management in GB; Section III presents studies investigating the performance of the services and actions employed by the GB Electricity System Operator (ESO) via two case studies; Section IV discusses the results of the system studies in context; and Section V concludes the paper outlining future work.

\section{FReQuenCy AND RoCoF IN GB}

At present, in GB, the frequency response services include Primary, Secondary, Enhanced and High frequency responses, as shown in Fig. 1, which are deployed to contain a frequency event due to a power imbalance as illustrated in Fig. 2. The technical definitions of these services are provided in Table I. Under European Network of Transmission System Operators for Electricity (ENTSO-E) definitions, Primary response is roughly equivalent to frequency containment reserve, Secondary response is equivalent to restoration reserve and reserve dispatch recovery is equivalent to replacement reserve [13].

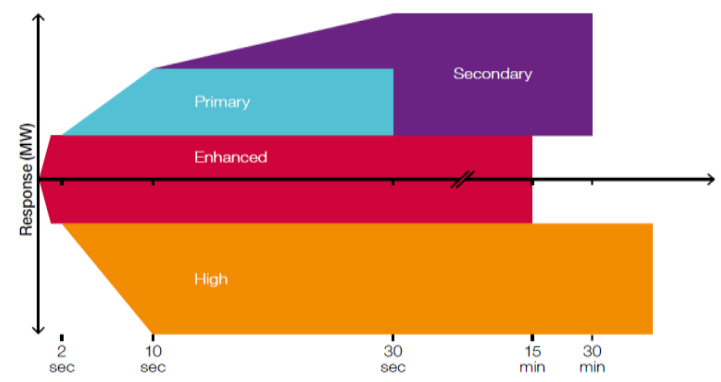

Fig. 1: Current GB frequency response services (Image Source: [4]).

With the exception of Enhanced frequency response (EFR), these responses can be dynamic or static. Dynamic frequency responses are response services that continuously track frequency deviations and provide the required response. Static frequency responses are frequency-triggered services that discreetly respond to frequency deviations when a given frequency threshold is reached.

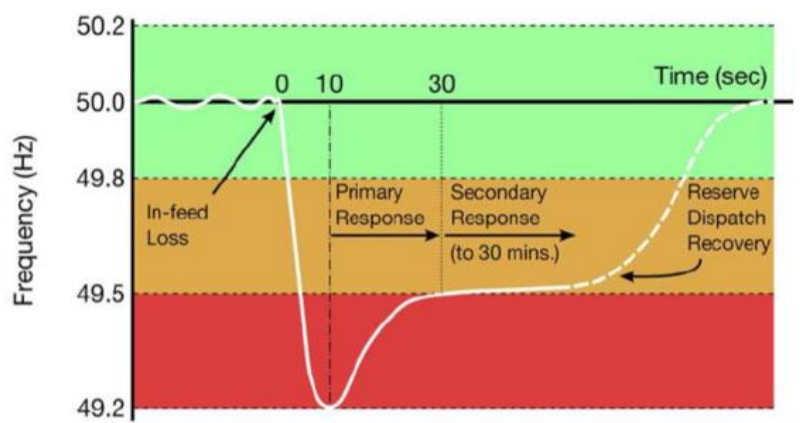

Fig. 2: Illustration of the operation of GB frequency response services (Image Source: [14]).

TABLE I. OVERVIEW OF FREQUENCY RESPONSE SERVICES [4, 15]

\begin{tabular}{|c|l|}
\hline Service Name & \multicolumn{1}{|c|}{ Technical Definition } \\
\hline $\begin{array}{c}\text { Primary } \\
\text { Reqponse }\end{array}$ & $\begin{array}{l}\text { Full delivery of active power response 10 seconds } \\
\text { after the event with a 2 second delay and sustained } \\
\text { for a further 20 seconds. }\end{array}$ \\
\hline $\begin{array}{c}\text { Secondary } \\
\text { Frequency } \\
\text { Response }\end{array}$ & $\begin{array}{l}\text { Full delivery of active power response 30 seconds } \\
\text { after the event and sustained for 30 minutes. }\end{array}$ \\
\hline $\begin{array}{c}\text { High Frequency } \\
\text { Response }\end{array}$ & $\begin{array}{l}\text { Full delivery of active power response 10 seconds } \\
\text { after the event with a 2 second delay and sustained } \\
\text { indefinitely. }\end{array}$ \\
\hline $\begin{array}{c}\text { Enhanced } \\
\text { Frequency } \\
\text { Response }\end{array}$ & $\begin{array}{l}\text { Full delivery of response for a 0.5 Hz change in } \\
\text { frequency and sustained for 15 minutes. This } \\
\text { service further defines a product with a maximum } \\
\text { of 500 ms detection and instruction delay, such that } \\
\text { the response is fully delivered within 1 second. }\end{array}$ \\
\hline
\end{tabular}

The ESO must manage frequency excursions within frequency limits. These limits are defined by the loss risk classifications and a definition of unacceptable frequency conditions in the Security and Quality of Supply Standard (SQSS), summarised in Table II.

TABLE II. DEFINITIONS OF LOSS RISK AND FREQUENCY CONDITIONS [16]

\begin{tabular}{|c|l|}
\hline $\begin{array}{c}\text { Normal Loss } \\
\text { Risk }\end{array}$ & $\begin{array}{l}\text { That level of loss of power in-feed risk which is covered } \\
\text { over long periods operationally by frequency response to } \\
\text { avoid a deviation of system frequency by more than 0.5 } \\
\text { Hz. Until 31st March 2014, this is 1000 MW. From April } \\
\text { 1st 2014, this is 1320 MW. However as described in [17] } \\
\text { this loss risk is still currently 1000 MW. }\end{array}$ \\
\hline $\begin{array}{c}\text { Infrequent } \\
\text { Loss Risk }\end{array}$ & $\begin{array}{l}\text { That level of loss of power in-feed risk which is covered } \\
\text { over long periods operationally by frequency response to } \\
\text { avoid a deviation of system frequency outside the range } \\
\text { 49.5 Hz to 50.5 Hz for more than 60 seconds. Until 31st } \\
\text { March 2014, this is 1320 MW. From April 1st 2014, this } \\
\text { is 1800 MW. However as described in [17] this loss risk } \\
\text { is still currently 1320 MW. }\end{array}$ \\
\hline
\end{tabular}




\begin{tabular}{|c|c|}
\hline $\begin{array}{l}\text { Jnacceptable } \\
\text { Frequency } \\
\text { Conditions }\end{array}$ & $\begin{array}{l}\text { These are conditions where: } \\
\text { i) the steady state frequency falls outside the statutory } \\
\text { limits of } 49.5 \mathrm{~Hz} \text { to } 50.5 \mathrm{~Hz} \text {; or } \\
\text { ii) a transient frequency deviation on the MITS persists } \\
\text { outside the above statutory limits and does not recover to } \\
\text { within } 49.5 \mathrm{~Hz} \text { to } 50.5 \mathrm{~Hz} \text { within } 60 \text { seconds. } \\
\text { Transient frequency deviations outside the limits of } 49.5 \\
\mathrm{~Hz} \text { and } 50.5 \mathrm{~Hz} \text { shall only occur at intervals, which ought } \\
\text { reasonably be considered as infrequent. It is not possible } \\
\text { to be prescriptive with regard to the type of secured event } \\
\text { which could lead to transient deviations since this will } \\
\text { depend on the extant frequency response characteristics } \\
\text { of the system which National Grid Electricity } \\
\text { Transmission shall adjust from time to time to meet the } \\
\text { security and quality requirements of this Standard. }\end{array}$ \\
\hline
\end{tabular}

Non-synchronous generators are increasingly displacing synchronous generators in the generation dispatch. Under the status quo, the displacement of synchronous generation reduces system inertia and increases RoCoF during a power imbalance. Furthermore, the displacement results in simultaneously reducing the Primary frequency response availability in terms of capacity and increasing frequency containment response requirement, due to the higher RoCoF experienced for a given loss event. Consequently, the reduction in system inertia leads to concerns regarding containing a frequency event within the acceptable limits both in terms of RoCoF and frequency.

Although the frequency response products do not specify any particular technology, conventional providers of dynamic frequency response services are synchronous generators. The GB ESO is aware of the challenges posed by the changing generation mix and has begun steps to improve the frequency response market and associated services [18]. In 2016, a oneoff tender for EFR was held and all the contracts to date have been awarded to battery storage [19]. The ESO has proposed further services including the future dynamic services as illustrated in Fig. 3, where both the Dynamic Balancing and Dynamic Containment services each have a detection and instruction delay of $500 \mathrm{~ms}$, and speed of delivery of $500 \mathrm{~ms}$ (i.e., each service is capable of fully delivering response within 1 second), with a deadband of $\pm 0.1 \mathrm{~Hz}$ and $\pm 0.2 \mathrm{~Hz}$ respectively. The proposed duration of the dynamic containment service is 20 minutes, while the duration of dynamic balancing service is still to be determined.

The ESO published [4] highlighting, among other factors, the limits to largest loss of demand or generation, which are constrained by the system inertia and RoCoF limit. The RoCoF limit in GB is $\pm 1 \mathrm{~Hz} / \mathrm{s}$ for new and existing generators with a delay of $500 \mathrm{~ms}$. However, synchronous power stations with greater than $5 \mathrm{MW}$ registered capacity commissioned between the $1^{\text {st }}$ of August 2014 and $31^{\text {st }}$ of July 2016 are permitted a RoCoF setting of $\pm 0.5 \mathrm{~Hz} / \mathrm{s}$ with a delay of $500 \mathrm{~ms}$ $[20,21]$. This means that a future GB power system is likely to experience scenarios where the effective RoCoF limit is $\pm 0.5 \mathrm{~Hz} / \mathrm{s}$.

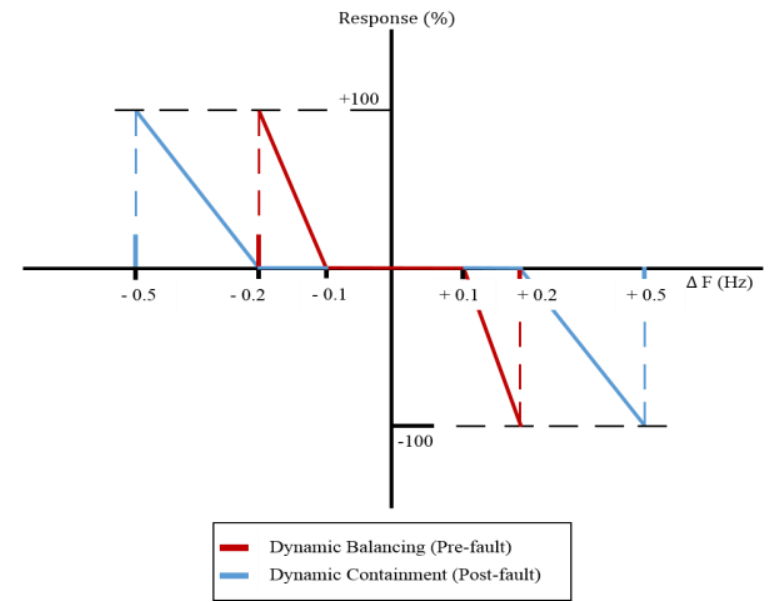

Fig. 3: National Grid's proposed dynamic response concept (adapted from [22]).

Although the original document gave existing synchronous and non-synchronous generators until the 1st July 2016 to make the relevant changes, coordinating and implementing these changes, particularly in reference to distributed generation, has proven challenging. As a result, there are about $2 \mathrm{GW}$ of distributed generation that are still using relays that could activate if RoCoF exceeds $\pm 0.125 \mathrm{~Hz} / \mathrm{s}$ [4]. This is significant since RoCoF relays are widely used in the UK and Ireland, as introduced in Section I. Consequently, due to the 2 GW of distributed generation still using the $\pm 0.125 \mathrm{~Hz} / \mathrm{s}$ RoCoF setting, $\pm 0.125 \mathrm{~Hz} / \mathrm{s}$ is currently the practical RoCoF limit in the GB power system, leading to a need to manage RoCoF within this limit during a frequency event, as discussed in [4].

\section{SYSTEM STUdIES}

Assessment of power system behaviour depends on use of detailed engineering models. Many of these are highly complex and make wide-ranging exploration of particular issues extremely challenging [23]. Thus, it is a wellestablished practice within the sector to use a variety of simplified models to address particular phenomena; examples include, the model used by the GB ESO in [24], and other single bus models in [25], [26], [27] and [28].

An in-house developed 'single bus' model described in [20] based on [24] has been used for the studies in this section. This model was developed in DigSILENT PowerFactory [29] specifically to assess a range of frequency response products in contrast to more generic models. It allows the convenient representation of different operational conditions, response providers and the accurate assessment of system frequency in response to different events on the GB transmission system.

Unless otherwise stated, the studies apply the following assumptions:

- demand is set at $20 \mathrm{GW}$ to illustrate the impact of low demand;

- in the context of this paper, 'Demand' refers to demand on the transmission system and includes pumping hydro, interconnector exports and net unmetered embedded generation; 
- embedded inertia is assumed to be applied as a function of total demand with an inertia constant of 1.83 seconds i.e., the inertia in GVAs is 1.83 multiplied by demand. This method, and the value of the inertia constant, is obtained from discussions with industry experts;

- demand provides an inherent active power response of $2.5 \% / \mathrm{Hz}[14]$;

- an inertia constant of 6 seconds is assumed for all gas units and 4 seconds for all other synchronous generators; these values are chosen following discussions with industry experts;

- generation is split into synchronous and non-synchronous generation;

- generation is further divided into flexible and nonflexible, where flexible generation can provide active power response, while non-flexible cannot;

- background generation is obtained from the ESO's future energy scenarios report under the gone green scenario for 2025 [21];

- in order to meet a given inertia target, generation is dispatched in the following order. Baseload power supply is first met by nuclear dispatched at $77 \%$ of the background capacity [30], gas plants are dispatched next to deliver the required Primary response until demand has been met or the inertia target has been achieved, or whichever of the two occurs first. If there is still a shortfall of demand it is met by dispatch from the remaining generation background but if the inertia target has been achieved the remaining demand is met by nonsynchronous dispatch;

- dynamic Primary response is delivered by flexible generation. Flexible generators are $75 \%$ loaded with response provided by $50 \%$ of the headroom [31];

- $\quad$ where applicable Enhanced response is dispatched at 201 MW, assuming that all capacity procured in the 2016 EFR tender is available [19] and no new capability has been procured;

- containment is attempted for the least containment reserve holding, and all response is assumed to be dynamic; and

- the delivery of responses is at the minimum technical requirements of their definitions, however, it is recognised that delivery of responses may in practice have a shorter delay or in some cases faster ramp rates.

The studies presented in this paper are an extension of the work done in [32], with changes made to the modelling dispatch and cases for consideration. Most importantly, in light of [22] where the ESO provides further clarity on the specifications of their future dynamic response services, the application of the dynamic containment service has been updated to match the current specifications of the service. The cases presented below, in Sections III.A and III.B, serve to illustrate the impact that curtailing the loss risk or procuring faster frequency response services have on the power system's ability to keep frequency and RoCoF within acceptable conditions during a normal loss of infeed event.
A. Case 1: Containing Normal Loss Risk Within $\pm 0.5 \mathrm{~Hz}$ of Nominal Frequency with a $\pm 0.125 \mathrm{~Hz} / \mathrm{s}$ RoCoF Limit

On the 7th of August 2016, the GB power system experienced a system inertia of $135 \mathrm{GVAs}$ with a transmission system demand of $16.3 \mathrm{GW}$. Due to the combination of a windy weekend with high output from wind and solar, and low demand from the 7th to the 8th of August 2016 the ESO had to curtail the loss risk in order to keep the power system secured [4]. Based on the operational scenario on the $7^{\text {th }}$ of August 2016, the study scenarios presented in this section are for a GB power system with $20 \mathrm{GW}$ of demand and $130 \mathrm{GVAs}$ of inertia, while RoCoF and frequency limits are applied under current definitions. These scenarios illustrate the performance of frequency response services and loss risk curtailment actions in the GB power system to manage the current normal loss risk.

To illustrate the impact of loss risk curtailment and faster frequency response services on frequency and $\mathrm{RoCoF}$ at low demand and inertia, the four scenarios that are presented in Table III are investigated. Table IV is an overview of the observations from the study, with Fig. 4 and 5 showing the frequency and RoCoF plots for scenarios A - D.

TABLE III. STUDY SCENARIOS FOR CONTAINING NORMAL LOSS RISK WITHIN \pm 0.5 Hz OF NOMINAL FREQUENCY WITH A \pm 0.125 Hz/s ROCOF LIMIT

\begin{tabular}{|c|l|}
\hline \multicolumn{1}{|c|}{ Title } & \multicolumn{1}{c|}{ Description } \\
\hline Scenario A & $\begin{array}{l}\text { Included as a reference scenario, the simulated loss is 1 } \\
\text { GW with only Primary response available to contain the } \\
\text { event. }\end{array}$ \\
\hline Scenario B & $\begin{array}{l}\text { The simulated loss is 1 GW with Primary, Enhanced and } \\
\text { the new Dynamic Containment frequency response } \\
\text { services dispatched to contain frequency deviation. }\end{array}$ \\
\hline Scenario $C$ & $\begin{array}{l}\text { The simulated loss is reduced from 1 GW to 650 MW, with } \\
\text { only Primary response dispatched to contain the frequency } \\
\text { deviation. }\end{array}$ \\
\hline Scenario $D$ & $\begin{array}{l}\text { The simulated loss is 1 GW with Enhanced and the new } \\
\text { Dynamic Containment frequency response services } \\
\text { dispatched to contain frequency deviation. }\end{array}$ \\
\hline
\end{tabular}

TABLE IV. OVERVIEW OF STUDY SCENARIOS AND OBSERVATIONS FOR CASE 1

\begin{tabular}{|c|c|c|c|c|}
\hline $\begin{array}{c}\text { Limulated } \\
\text { Loss }\end{array}$ & $1 \mathrm{GW}$ & $1 \mathrm{GW}$ & C & D \\
\hline $\begin{array}{c}\text { RoCoF } \\
\text { Contained }\end{array}$ & No & No & Yes & $1 \mathrm{GW}$ \\
\hline $\begin{array}{c}\text { Frequency } \\
\text { Contained }\end{array}$ & No & Yes & Yes & Yes \\
\hline $\begin{array}{c}\text { Dispatched } \\
\text { Responses }\end{array}$ & Primary & $\begin{array}{c}\text { Primary, } \\
\text { Enhanced and } \\
\text { Dynamic } \\
\text { Containment }\end{array}$ & Primary & $\begin{array}{c}\text { Enhanced and } \\
\text { Dynamic } \\
\text { Containment }\end{array}$ \\
\hline
\end{tabular}

It is demonstrated by Scenario $\mathrm{C}$ that curtailing the loss risk to manage frequency stability within RoCoF and frequency limits is the only viable scenario of the four presented in this case study. 
There are two factors that determine acceptable frequency behaviour during a power imbalance: the maximum frequency deviation (nadir or zenith) and RoCoF. Consequently, the system must be secured against the normal loss risk in terms of both these factors. Scenario C simulates a $650 \mathrm{MW}$ loss risk because that is the loss risk limit, based on the swing equation [7], for a $130 \mathrm{GVAs}$ power system with a $\pm 0.125 \mathrm{~Hz} / \mathrm{s} \mathrm{RoCoF}$ limit. Although, in principle, the ESO should accept a loss of infeed of up to $1 \mathrm{GW}$ and tolerate a frequency deviation that is no bigger than $\pm 0.5 \mathrm{~Hz}$, in this case study the system must be dispatched such that no single loss risk exceeds $650 \mathrm{MW}$. The output of any single unit exceeding that level must be curtailed so that it does not. An alternative is to re-dispatch the power system to increase inertia, since the loss risk limit calculated using the swing equation is higher with more inertia for the same RoCoF limit.

It is observed in Fig. 4 that while Scenario A produces a frequency behaviour that exceeds acceptable frequency conditions for a normal loss risk, Scenario C successfully contains the event within frequency conditions due to the reduced loss risk, even though both scenarios only deploy Primary response.

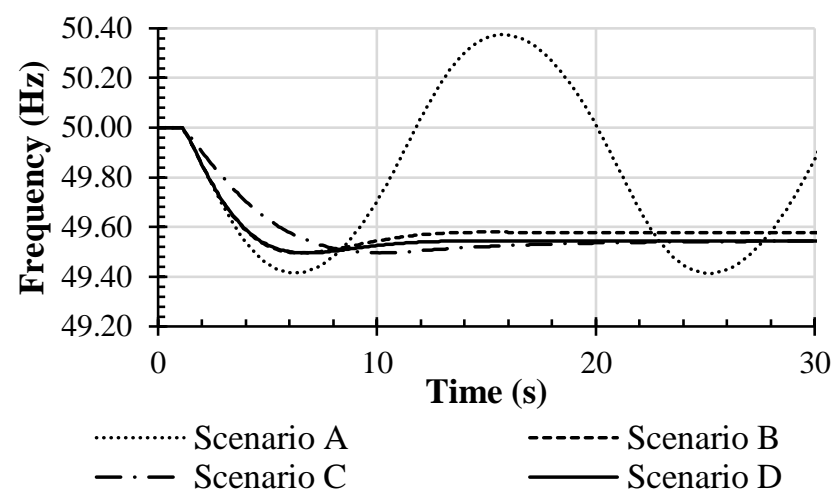

Fig. 4: Frequency plots comparing the impact of different actions to meet operational limits for a system with $130 \mathrm{GVAs}$ of inertia.

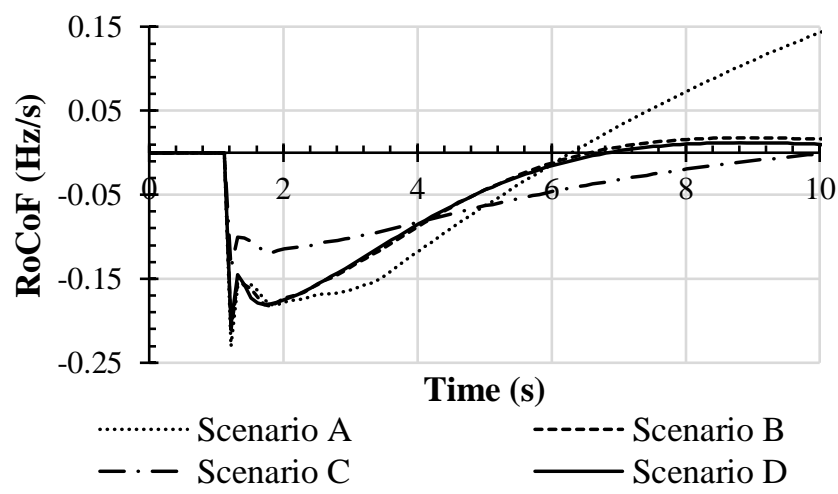

Fig. 5: RoCoF plots comparing the impact of different actions to meet operational limits for a system with $130 \mathrm{GVAs}$ of inertia.

In Scenarios B and D in Fig. 4 and 5, it is shown that while the inclusion of faster dynamic frequency response services such as Enhanced response and the Dynamic Containment concept contains frequency within acceptable conditions,
RoCoF limits are violated. This is because the service definitions for the faster services have no impact on RoCoF, particularly in reference to the current limit of $\pm 0.125 \mathrm{~Hz} / \mathrm{s}$, which typically includes a detection window of $100 \mathrm{~ms}$ or less.

\section{B. Case 2: Containing Normal Loss Risk Within $\pm 0.5 \mathrm{~Hz}$ of Nominal Frequency and $a \pm 0.5 \mathrm{~Hz} / \mathrm{s}$ RoCoF Limit}

The previous case study considered containment of a normal loss risk based on the $7^{\text {th }}$ of August 2016 operational scenario, with a RoCoF limit of $\pm 0.125 \mathrm{~Hz} / \mathrm{s}$. However, it is conceivable that, in the future, unless the relevant plants are decommissioned, or otherwise not in merit, the RoCoF limit in the GB power system will be $\pm 0.5 \mathrm{~Hz} / \mathrm{s}$. Therefore, the impact of faster response services during a credible loss event should be assessed for operational scenarios with a $\pm 0.5 \mathrm{~Hz} / \mathrm{s} \mathrm{RoCoF}$ limit where the present $(1 \mathrm{GW})$ and future $(1.32 \mathrm{GW})$ normal loss risk conditions are considered. According to the swing equation, the minimum system inertia values for the cases being considered here are 50 GVAs (for the current normal loss risk) and 66 GVAs (for the future normal loss risk).

TABLE V. STUDY SCENARIOS FOR CONTAINING NORMAL LOSS RISK WITHIN $\pm 0.5 \mathrm{HZ}$ OF NOMINAL FREQUENCY WITH A $\pm 0.5 \mathrm{~Hz} / \mathrm{S}$ ROCOF LIMIT

\begin{tabular}{|c|l|}
\hline Title & \multicolumn{1}{c|}{ Description } \\
\hline Scenario $A$ & $\begin{array}{l}\text { Included as a reference scenario with only Primary } \\
\text { response available to contain the event }\end{array}$ \\
\hline Scenario B & $\begin{array}{l}\text { Primary and Enhanced frequency response services } \\
\text { dispatched to contain frequency deviation. }\end{array}$ \\
\hline Scenario $C$ & $\begin{array}{l}\text { Primary, Enhanced and the Dynamic Containment } \\
\text { frequency response services dispatched to contain } \\
\text { frequency deviation. }\end{array}$ \\
\hline Scenario D & $\begin{array}{l}\text { Enhanced and the new Dynamic Containment frequency } \\
\text { response services dispatched to contain frequency } \\
\text { deviation. }\end{array}$ \\
\hline
\end{tabular}

TABLE VI. OVERVIEW OF STUDY SCENARIOS AND OBSERVATIONS IN CASE 2

\begin{tabular}{|c|c|c|c|c|}
\hline A & B & C & D \\
\hline $\begin{array}{c}\text { Frequency } \\
\text { Contained }\end{array}$ & No & No & Yes & Yes \\
\hline $\begin{array}{c}\text { Frequency } \\
\text { Stable }\end{array}$ & No & No & Yes & Yes \\
\hline $\begin{array}{c}\text { Dispatched } \\
\text { Responses }\end{array}$ & Primary & $\begin{array}{c}\text { Primary and } \\
\text { Enhanced }\end{array}$ & $\begin{array}{c}\text { Primary, } \\
\text { Enhanced } \\
\text { and } \\
\text { Dynamic } \\
\text { Containment }\end{array}$ & $\begin{array}{c}\text { Enhanced } \\
\text { and } \\
\text { Dynamic } \\
\text { Containment }\end{array}$ \\
\hline
\end{tabular}

Four scenarios are presented in Table $\mathrm{V}$ for investigation, which compare the performance of different frequency response actions. An overview of the study scenarios is presented in Table VI, and the resultant frequency plots are presented in Fig. 6 for a $1 \mathrm{GW}$ normal loss risk, and Fig. 7 for a $1.32 \mathrm{GW}$ normal loss risk. A similar trend is observed in both Fig. 6 and Fig. 7, indicating that while the addition of 201 MW of EFR to the already procured Primary response raises the frequency nadir in Scenario B when compared to Scenario 
A, both scenarios breach the acceptable frequency conditions for a normal loss risk. This oscillation observed here, similar to that seen in Scenario A of Fig. 4, is attributed to the inadequacy of the response service that is insufficiently fast to contain the event. However, it is arguable that this behaviour could be remedied by modifying the simple proportional controller applied in the studies presented in this paper. A proportional controller was used here to represent the worstcase controller behaviour of the providers of the response services.

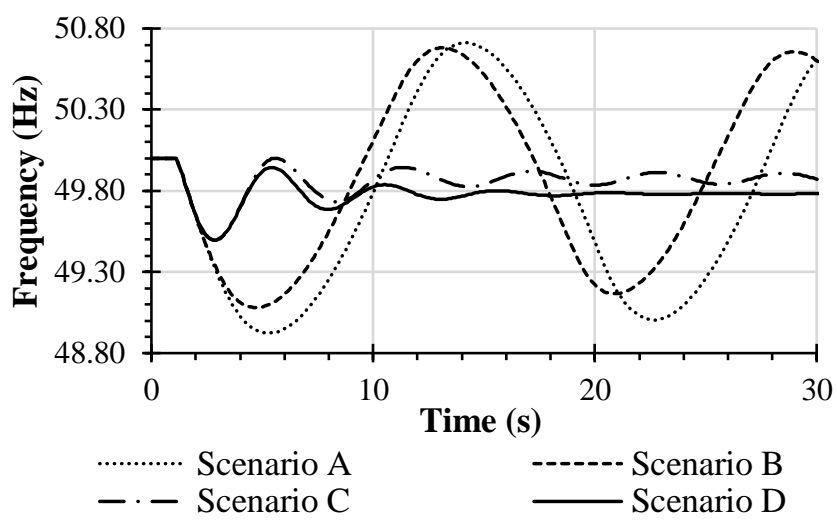

Fig. 6: Frequency plots for $1 \mathrm{GW}$ loss at 50 GVAs.

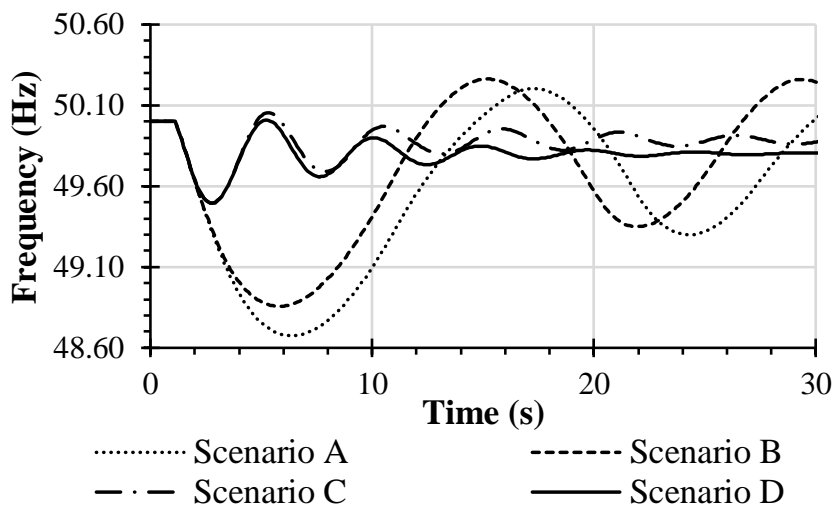

Fig. 7: Frequency plots for $1.32 \mathrm{GW}$ loss at 66 GVAs.

The inclusion of the Dynamic Containment service in Scenario C contains the event and provides a reasonably well damped frequency oscillation after containment. That said, completely displacing Primary response with the Dynamic Containment service shows a more pronounced dampening effect in Scenario D.

It is expected that the trends observed in this case study will continue as the inertia in the power system reduces towards the minimum inertia for a $\pm 1 \mathrm{~Hz} / \mathrm{s}$ RoCoF limit and corresponding loss risk. It can be said that with a relaxed RoCoF limit, the activation delay, and indeed the speed of full delivery, of the frequency containment services becomes more important for stable containment of frequency within RoCoF and frequency limits, since at lower inertia frequency limits would be reached sooner than at higher inertia and would need to be contained by a sufficiently fast response service. The expression presented in the appendix can be used as a rough estimation of the turning point(s) of the frequency trend due to the action of a given containment service in response to a frequency event.

\section{DISCUSSION}

By considering the results of Section III, the following observations are made:

1) Given the frequency response services currently available in GB, at low demand and low inertia, the current practical RoCoF limit can only be managed by curtailing the loss risk or increasing the inertia in the power system.

2) Fast response with a $500 \mathrm{~ms}$ detection and instruction delay such as that proposed by the ESO has no impact on the initial RoCoF experienced by the power system following a power imbalance. That said, further increasing the speed of the response service improves the impact on RoCoF, e.g., deploying synthetic inertia controllers that have typical response times between 50 and $200 \mathrm{~ms}$ [33].

3) Once the GB power system is no longer constrained by the $\pm 0.125 \mathrm{~Hz} / \mathrm{s}$ RoCoF limit, the critical actions will tend towards dispatching additional containment reserve above the $201 \mathrm{MW}$ of EFR that supports the already existing Primary response. At the lower system inertia permitted by relaxed RoCoF settings, containing the loss risk becomes more of an issue of adequacy of dynamic frequency containment services.

4) As the GB power system tends towards lower inertia, frequency containment reserves will increasingly need to be met by faster acting services, supplementing traditional Primary reserves that are not quick enough alone.

According to the ESO's report in [34], by 2025/26 the loss limit would be $650 \mathrm{MW}$ about $25 \%$ of the time in order to comply with a practical RoCoF limit of $\pm 0.125 \mathrm{~Hz} / \mathrm{s}$. This means that BritNed, a $1 \mathrm{GW}$ interconnector, would have to be curtailed by $350 \mathrm{MW}$. A constrained interconnector for $25 \%$ of the year means that a total of $705.6 \mathrm{GWh}$ of imports over BritNed would have been prevented from being used. The ESO in [5] puts the cost of curtailing loss risk as a solution to the issue of meeting the RoCoF limit of $\pm 0.125 \mathrm{~Hz} / \mathrm{s}$ at $£ 268 \mathrm{~m}$ per annum by 2020 , expected to increase year by year. The system operator in Ireland curtails wind to address RoCoF and frequency concerns, among other things [27, 35]. However, the Irish power system utilises the system non-synchronous penetration limit (SNSP) as a metric to guide power system operation and keep within statutory limits for credible loss of infeed events. Furthermore, steps have been taken in Ireland to mitigate the RoCoF and frequency stability risks via system services proposed in the Delivering a Secure, Sustainable Electricity System (DS3) project [36], which include new products such as synchronous inertial response and fast frequency response capable of responding within $150-300$ ms [37], and reducing the minimum stable generation of thermal plants to increase system inertia without having to curtail more wind [38].

Curtailing generation or interconnector imports and exports to contain the loss risk already takes place in GB [4]. While it 
is currently a viable option, it is projected that in the future the costs associated with curtailment will increase, fuelled in part by more interconnector capacity [4]. Dispatching more deloaded synchronous plants or deploying synchronous compensation are potential alternatives that would increase the inertia in the power system while providing additional benefits such as reactive power and short circuit current, reducing the need to curtail the loss risk. In the case of the deployment of synchronous compensation, the costs and benefits are being considered [39].

In Case 1 the RoCoF exceeds the current $0.125 \mathrm{~Hz} / \mathrm{s}$ limit for $1 \mathrm{GW}$ loss. A plan is in place in GB to update the RoCoF settings, but it is not scheduled to be completed until 2022 [40]. Acceleration of this programme would reduce the total number of hours for which the output of the largest infeed would need to be curtailed.

Lastly, the third and fourth points outlined at the start of this section highlight the need for fast acting frequency containment services, especially at low demand and inertia. Although the probability of the GB power system operating at low inertia levels sub 75 GVAs is extremely low before 2025 [4], such a level of inertia will become more likely as the power system tends towards a greater percentage penetration of converter connected generation and accompanying closure of synchronous plant. Services such as the Dynamic Containment frequency response concept are a step in the right direction. However, while wind turbines can provide such responses -and few conventional synchronous plant will normally have been scheduled to be available to provide a response service under high wind conditions- the current service design and market structure precludes the participation of wind farms. This is because the current market structure for commercial frequency response is a month-ahead market [41], a timescale that is prohibitive for wind plants due to the limited predictability of the wind resource beyond a few days [42]. Similarly, a persistent response for 20 minutes provides challenges for such providers; however, these are not insurmountable and can be overcome by strategies such as deploying complementary storage or deloading. Aside from this there is also the practical challenge, namely: there is currently no real distinction between dynamic Primary and dynamic Secondary response for generators providing the service. This is because, in practice, dynamic Secondary response in GB is an extension of dynamic Primary response. Plants providing these services will typically perform an action during a power imbalance that meets both service requirements without further action on the part of the plant operator. Furthermore, the procurement of Primary, Secondary and High frequency responses as a bundle is a barrier to participation for some providers, such as wind plants, in the commercial frequency response market. That said, it is worth noting that at the time of writing the GB ESO is running trials to investigate ways to improve market practices towards furthering increased participation [43]. Nonetheless, it is likely that an unbundling of future frequency containment and restoration services would provide benefits to the power system and allow the technologies that are displacing synchronous generators participate in frequency response services that mitigate the impact of the changing power landscape in terms of frequency stability. This will give providers the opportunity to participate in either or both frequency containment and restoration services depending on their capabilities and inclination.

\section{CONClusions AND FUTURE WORK}

This paper has investigated the impact of credible single loss of infeed events in respect of statutory limits on system frequency and practical limits on RoCoF. However, it also shows that traditional Primary frequency response services are unsuitable for adequately managing loss risks as RoCoF approaches $\pm 1 \mathrm{~Hz} / \mathrm{s}$.

At the time of writing, the RoCoF limit is the critical constraint, and the ESO can ensure frequency stability by either curtailing the loss risk or increasing the inertia in the power system. However, there are disadvantages associated with both options including limiting interconnector imports or the uptake of wind and incurring additional significant balancing costs. That said, the impact can be minimised by reducing the minimum stable generation of thermal plants.

In a low inertia power system that is no longer constrained by the $\pm 0.125 \mathrm{~Hz} / \mathrm{s}$ RoCoF limit, maintaining acceptable frequency conditions would become the dominant constraint. However, this paper shows that traditional Primary frequency response services are unsuitable for adequately managing loss risks as RoCoF approaches $\pm 1 \mathrm{~Hz} / \mathrm{s}$. Consequently, managing the credible loss risk will be dependent on the deployment of fast acting frequency containment services, such as the Dynamic Containment response concept.

The next steps of the work presented in this paper include quantifying the impact of the current and future practical RoCoF limits in terms of the 'system non-synchronous penetration limit' (SNSP), i.e., the maximum amount of wind, solar and HVDC interconnector imports that the system can accept at any one time. Future work by the authors will also include investigating the benefits of incorporating virtual synchronous machines with fast acting response services and their impact to frequency behaviour during a frequency event. Furthermore, the structure of future frequency response services will be investigated in detail to investigate the viability and impact of unbundling the frequency response services, to understand how those services will interact to contain a loss event within frequency limits.

\section{REFERENCES}

[1] National Grid, "Electricity Ten Year Statement 2016," 2016. [Online]. Available: https://tinyurl.com/ycxuzrox. [Accessed 1809 2017].

[2] Department for Business, Energy and Industrial Strategy, "Implementing the end of unabated coal by 2025: Government response to unabated coal closure consultation," 2018.

[3] Department for Business, Energy and Industrial Strategy, "Coal generation in Great Britain: The pathway to a low carbon future consultation document," 2016.

[4] National Grid, "Appendices to the technical report on the events of 9 August 2019," $06092019 . \quad$ [Online]. Available: https://tinyurl.com/y3oahr5f. [Accessed 0710 2019]. 
[5] National Grid, "Enhanced frequency control capability (EFCC)," 10 2014. [Online]. Available: https://tinyurl.com/h3k4rgw. [Accessed 0102 2017].

[6] P. Tielens and D. V. Hertem, "The relevance of inertia in power systems," Renewable and Sustainable Energy Reviews, vol. 55, pp. 9991009, 2016.

[7] P. Kundur, Power System Stability and Control, McGraw-Hill Inc., 1994.

[8] H. Urdal, "Impact on T\&D protection systems from low fault," in Substation Technology 2009: Analysing the Strategic and Practical Issues of Modern Substation, Birmingham, 2009.

[9] H. Urdal, R. Lerna, J. Zhu, C. Ivanov and A. Dahresobh, "System strength considerations in a converter dominated power system," IET Renewable Power Generation, vol. 9, no. 1, pp. 10 - 17, 2015.

[10] P. Crolla, A. J. Roscoe, A. Dysko and G. M. Burt, "Methodology for testing loss of mains detection algorithms for microgrids and distributed generation using real-time power hardware-inthe-loop based technique," in 8th International Conference on Power Electronics - ECCE Asia, The Shilla Jeju, 2011.

[11] A. Dysko, "Loss of Mains Protection," [Online]. Available: http://tinyurl.com/mtt8mop. [Accessed 1105 2017].

[12] Adrianti and A. Dysko, "Risk Assessment Analysis to Find Optimum ROCOF Protection Settings," in 12th IET International Conference on Developments in Power System Protection (DPSP 2014), Copenhagen, 2014.

[13] Enstoe, "Network Code on Load-Frequency Control and Reserves," 28 June 2013. [Online]. Available: https://tinyurl.com/m2hkmeu. [Accessed 1905 2017].

[14] P. M. Ashton, C. S. Saunders, G. A. Taylor, A. M. Carter and M. E. Bradley, "Inertia estimation of the GB power system using synchrophasor measurements," IEEE Trans. on Power Systems, vol. 30, no. 2, pp. $701-709,2015$.

[15] National Grid, Enhanced Frequency Response Seminar, Webinar, 2016.

[16] National Grid, "National Electricity Transmission System Security and Quality of Supply Standard," 802 2017. [Online]. Available: https://tinyurl.com/y43vdub5. [Accessed 1802 2019].

[17] Ofgem, "Letter: National Electricity Transmission System Security and Quality of Supply Standard: Normal Infeed Loss Risk (GSR015)," 2014. [Online]. Available: https://tinyurl.com/ybd969d4. [Accessed 1801 2018].

[18] National Grid, "Future frequency response products," 04 2018. [Online]. Available: https://tinyurl.com/ybdbfa34. [Accessed 1004 2018].

[19] National Grid, "Enhanced frequency response market information report," 2608 2016. [Online]. Available: https://tinyurl.com/y6phwth3. [Accessed 1702 2019].

[20] M. Nedd, Q. Hong, K. Bell, C. Booth and P. Mohapatra, "Application of synchronous compensators in the GB transmission network to address protection challenges from increasing renewable generation," in 2017 CIGRE B5 Colloquium, Auckland, 2017.

[21] National Grid, "Future Energy Scenarios," 07 2016. [Online]. Available: https://tinyurl.com/ofeyeys. [Accessed 2102 2017].

[22] National Grid, "Faster acting response webinar," 1403 2018. [Online]. Available: https://tinyurl.com/ybnla3fw. [Accessed 2806 2018].

[23] K. R. W. Bell and A. N. D. Tleis, "Test system requirements for modelling future power systems," in General Meeting of the Power and Energy Society (PES), Minneapolis, Minnesota, 2010.

[24] National Grid, "GC022 - Frequency Response," 0901 2013. [Online]. Available: https://tinyurl.com/y65gmkaz. [Accessed 2109 2017].

[25] M. Yu, A. J. Roscoe, A. Dyśko, C. D. Booth, R. Ierna, J. Zhu and H. Urdal, "Instantaneous penetration level limits of nonsynchronous devices in the British power system," IET Renewable Power Generation, vol. 11, no. 8, pp. 1211 - 1217, 2016.

[26] K. Máslo, A. Kasembe, S. Moroni and R. Pestana, "Frequency Stability Modelling of the Future Continental Europe Power System," in 52nd International Universities' Power Engineering Conference, Heraklion, 2017.

[27] J. O'Sullivan, A. Rogers, D. Flynn, P. Smith, A. Mullane and M.
O'Malley, "Studying the maximum instantenous non-synchronous generation in an island system-frequency stability challenges in Ireland," IEEE TRANSACTIONS ON POWER SYSTEMS, vol. 29, no. 6, pp. 2943 2951, 2014.

[28] J. Undrill, "Primary frequency response and control of power system frequency," 02 2018. [Online]. Available: https://tinyurl.com/yboca8fh. [Accessed 2201 2019].

[29] DigSilent, "PowerFactory," 2017. [Online]. Available: https://tinyurl.com/nxe4fta. [Accessed 1905 2017].

[30] BEIS, "Nuclear capacity in the UK," 03 2017. [Online]. Available: http://tinyurl.com/yyody2h7. [Accessed 1302 2019].

[31] National Grid, "Frequency response technical sub-group report Version 1.0," 1511 2011. [Online]. Available: https://tinyurl.com/y2eg53be. [Accessed 1802 2019].

[32] M. Nedd, K. Bell and C. Booth, "Containing loss risk in a low inertia GB power system," in IEEE International Conference on Environment and Electrical Engineering and 2018 IEEE Industrial and Commercial Power Systems Europe (EEEIC / I\&CPS Europe), Palermo, 2018.

[33] B. Hartmann, I. Vokony and I. Taczi, "Effects of decreasing synchronous inertia on power system dynamics-Overview of recent experiences and marketisation of services," International Transactions on Electrical Energy Systems, 16072019.

[34] National Grid, "System Operability Framework 2016," 2016. [Online]. Available: https://tinyurl.com/yad6pju8. [Accessed 1809 2017].

[35] EirGrid and SONI, "Annual renewable energy constraint and curtailment report 2018," $052019 . \quad$ [Online]. Available: https://tinyurl.com/y5325gy5. [Accessed 0710 2019].

[36] EirGrid and SONI, "DS3 System Services: Portfolio Capability Analysis," 11 2014. [Online]. Available: https://tinyurl.com/y4gaov75. [Accessed 2102 2019].

[37] D. Pratt, "Ireland's fast-response grid services market could be like 'EFR on steroids', expert says," Energy Storage News, 1910 2018. [Online]. Available: https://tinyurl.com/yydkrbur. [Accessed 2102 2019].

[38] M. L. Kubik, P. J. Coker and J. F. Barlow, "Increasing thermal plant flexibility in a high renewables power system," Applied Energy, vol. 154, pp. $102-111,2015$.

[39] Ofgem, "Electricity Network Innovation Competition: 2016 Funding Decision," 3011 2016. [Online]. Available: https://tinyurl.com/hk29g4j. [Accessed 2302 2017].

[40] Energy Networks Association, "Accelerated Loss of Mains Change Programme (ALoMCP),” 2019. [Online]. Available: https://tinyurl.com/y5pr6n4b. [Accessed 0310 2019].

[41] National Grid, "Firm Frequency Response (FFR) market information report for Oct-18," 08 2018. [Online]. Available: https://tinyurl.com/yxtow4nh. [Accessed 1802 2019].

[42] B. O'Neill, "Forecasting Wind," 3003 2016. [Online]. Available: https://tinyurl.com/y5rbokfr. [Accessed 1802 2019].

[43] National Grid, "Product roadmap for frequency response and reserve," 12 2017. [Online]. Available: https://tinyurl.com/y914fl76. [Accessed 18 02 2019].

\section{APPENDIX}

A closed form solution to the swing equation following a power imbalance while under idealistic conditions still provides some useful insights. Here we consider this situation with frequency response provided via a simplified droop characteristic but with a fixed time delay. Beginning with the swing equation

$$
2 H \frac{\partial \Delta f}{\partial t}=R(t)-P(t)
$$

where $H$ is the system inertia constant, $\Delta f(t)$ is the 
frequency deviation from nominal, $t$ is time, $R(t)$ is frequency response power, and $P(t)$ is the lost power infeed which is equal to 0 for $t<0$ and $P_{L}$ for $t \geq 0$. Consider a response which is proportional to the frequency but with some delay $l$ and rate of delivery $d$ such that $R(t)=-d \times \Delta f(t-l)$. This problem can be solved exactly. In the region $t<0$ the solution is trivial as all variables are zero. In the region $0 \leq$ $t<l$ the loss has occurred but response has not activated, so

$$
2 H \frac{\partial \Delta f}{\partial t}=-P_{L}
$$

and is easily solved, noting that $\Delta f(0)=0$, to give

$$
\Delta f(t)=-\frac{P_{L}}{2 H} t .
$$

In the next period from $l \leq t<2 l$, the response has activated and $R(t)=d \frac{P_{L}}{2 H}(t-l)$ yielding

$$
2 H \frac{\partial \Delta f}{\partial t}=d \frac{P_{L}}{2 H}(t-l)-P_{L},
$$

which may also be solved in the same manner imposing the constraint that $\Delta f(t)$ is continuous at $t=l$.

The general solution for $(N-1) l \leq t<N l$ yields a polynomial in $t$ of order $N$ given by

$$
\begin{aligned}
\Delta f(t)=\sum_{n=1}^{N}\left[\frac{(-t)^{n} d^{n-1} P_{L}}{n !(2 H)^{n}}\right. & \\
& \left.+\sum_{m=1}^{n-1} \frac{((1-m) l)^{n-m} d^{n-m-1} t^{m} P_{L}}{(n-1) ! m !(2 H)^{n-m}}\right] .
\end{aligned}
$$

This expression enables the definition of all turning points of the frequency trace unto time $t=N l$ for a given $l, d, H$ and $P_{L}$. These may then be used to quickly assess frequency containment and the stability of the system without the need for computationally demanding simulation studies.

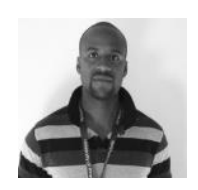

Marcel Nedd is currently a student in the final year of the CDT in future power networks and smart grids at the University of Strathclyde in Glasgow, Scotland. He received the M.Sc. degree in environmental sustainability and green technology from Keele University, Newcastle-under-Lyme, UK, in 2011 and the B.Sc. degree in physics from Nottingham Trent University, Nottingham, UK, in 2009. His current research interests include future electrical power systems, power system protection, inertia, rate of change of frequency and frequency response.

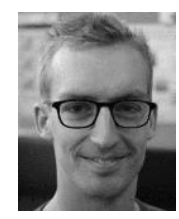

Jethro Browell (S'15--M'16) received the M.Phys. degree in Mathematics and Theoretical Physics from the University of St Andrews, UK, in 2011 and a Ph.D. in wind energy systems from The University of Strathclyde, UK, in 2015. He is a Research Fellow at the University of Strathclyde's Institute for Energy and Environment where his research interests span all aspects of energy forecasting and associated decision-making in electricity markets and power system operation. He is an EPSRC Innovation Fellow and a member of the IEEE Power $\backslash \&$ Energy Society.

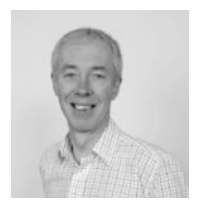

Keith Bell is the ScottishPower Professor of Smart Grids at the University of Strathclyde and, since May 2014, a co-Director of the UK Energy Research Centre. He joined the University in 2005 having previously worked as a researcher in Bath, Manchester and Naples and as a system development engineer in the electricity supply industry in Britain. He is active in CIGRE and is a member of the Executive Committee of the Power Systems Computation Conference and of the Executive of the IET Power Academy, an initiative to promote electric power engineering as a graduate career in the UK. He is a Chartered Engineer and, at different times, has advised the Scottish Government, the Republic of Ireland government, the Northern Ireland Executive, Ofgem and the UK government on power systems issues as well as leading a number of engineering research projects in collaboration.

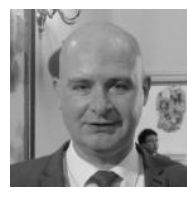

Campbell Booth received the B.Eng. and Ph.D. degrees in electrical and electronic engineering from the University of Strathclyde, Glasgow, U.K., in 1991 and 1996, respectively, where he is currently a Professor and the Head of the Department for Electronic and Electrical Engineering. His research interests include power system protection, plant condition monitoring and intelligent asset management, applications of intelligent system techniques to power system monitoring, protection, and control, knowledge management, and decision support systems 